\title{
Quantitative Aspects of the Mutant Analysis by PCR and Restriction Enzyme Cleavage (MAPREC)
}

\author{
Zhengbin Lu, Monica P. Douthitt, Rolf E. Taffs, Yuxin Ran, Laurie P. Norwood, \\ and Konstantin M. Chumakov
}

Center for Biologics Evaluation and Research, Food and Drug Administration, Bethesda, Maryland 20892

\begin{abstract}
Quantitation of virus revertants by $P C R$ and restriction enzyme cleavage may give nonlinear results and, in some cases, produce artifacts caused by nucleotide misincorporation and heteroduplex formation, occurring during PCR. Modifications of the procedure allowed us to overcome these problems and develop a highly sensitive and reliable method of mutant quantitation. This procedure can be used to assess the quality of live vaccines and to study heterogeneity of viral and bacterial populations.
\end{abstract}

$\mathbf{R}$ phism studies combined with PCR technology provide a powerful tool for quantitative determination of genetic diversity within populations of viruses and bacteria. Recently, we demonstrated that mutant analysis by PCR and restriction enzyme cleavage (MAPREC) is an extremely sensitive assay capable of detecting and quantitating a minor fraction $(<1 \%)$ of revertants with $C$ instead of $U$ at nucleotide 472 (472-C) in type 3 oral poliovirus vaccine (OPV). ${ }^{(1,2)}$ The relative abundance of these revertants strongly correlated with results of a neurovirulence test in monkeys, suggesting that this molecular procedure can be used to evaluate consistency of Sabin vaccine lots. ${ }^{(3)}$ Our studies with different muta- tions in attenuated polioviruses showed that MAPREC assay may, in some cases, produce nonlinear results, complicating mutant quantitation. Here, we report a study of the observed nonlinearity and suggest the modified procedure that produces linear results. The data presented in this communication pertain to the fidelity of DNA amplification and may have implications for other methods involving PCR.

\section{MATERIALS AND METHODS}

\section{Original MAPREC Procedure}

The original MAPREC procedure and the primers used for PCR were described previously $^{(1)}$ and are listed in Table 1.

TABLE 1 PCR Primers and Restriction Enzymes Used to Quantitate Mutations by MAPREC

\begin{tabular}{|c|c|c|c|c|c|}
\hline $\begin{array}{l}\text { OPV type } \\
\text { (nucleotide) }\end{array}$ & $\begin{array}{l}\text { Primer } \\
\text { polarity }^{\mathrm{a}}\end{array}$ & $\begin{array}{l}\text { Primer } \\
\text { name }\end{array}$ & Primer sequence & $\begin{array}{l}\text { Restriction } \\
\text { enzymes } \\
\text { (vaccine: } \\
\text { revertant) }\end{array}$ & $\begin{array}{l}\text { Mutation } \\
\text { type } \\
\text { (vaccine: } \\
\text { revertant) }\end{array}$ \\
\hline \multirow[t]{2}{*}{$1(480)$} & sense & $\mathrm{pS}-1 / 453$ & (421)AGCCTAT TGGGCT ACATAAGAATCCTCCGGCCC(453) & \multirow[t]{2}{*}{ AluI:Aval } & \multirow[t]{2}{*}{ 480-G:480-A } \\
\hline & *antisense & $\mathrm{pA}-1 / 482$ & (513)CGACAGGCCAATCACTGGTTTGTGACCACCAG(482) & & \\
\hline \multirow[t]{3}{*}{$2(481)$} & sense & $\mathrm{pS}-2 / 465$ & (431)GCT ACATAAGAGTCCTCCGGCCCCTGAATGCGGCT(465) & \multirow{3}{*}{$\begin{array}{l}\text { AfllII: } \\
\text { Bsp } 1286 \mathrm{I}^{\mathrm{b}} \\
\text { Alu } \mathrm{I}^{\mathrm{d}}\end{array}$} & \multirow[t]{3}{*}{ 481-A:481-G } \\
\hline & *antisense & $\mathrm{pA}-2 / 483$ & (520)CGCGTTACGACAAGCCAGTCACTGGTTCGCGACCACGT(483) & & \\
\hline & ${ }^{*}$ antisense ${ }^{\mathrm{c}}$ & $\mathrm{pA}-2 / 482$ & (520)CGCGTT ACGACAAGCCAGTCACTGGT TCGCGACCGCCAG(482) & & \\
\hline \multirow[t]{2}{*}{$3(472)$} & *sense & $\mathrm{pS}-3 / 470$ & (431)TGAGCTACATGAGAGTGCTCCGGCCCCTGAATGCGGCTGA(470) & \multirow[t]{2}{*}{ Hinfl:MboI } & \multirow[t]{2}{*}{$472-\mathrm{T}: 472-\mathrm{C}$} \\
\hline & antisense & $\mathrm{pA}-3 / 484$ & (513)CAGGCTGGCTGCTGGGT TGCAGCTGCCTGC(484) & & \\
\hline \multirow[t]{3}{*}{$3(537)$} & *sense & $\mathrm{pS}-3 / 536$ & (507)CAGCCTGTCGTATCGCGCAAGTCCGTGTCG(536) & \multirow[t]{3}{*}{ NlaIV:TaqI } & \multirow[t]{3}{*}{ 537-G:537-A } \\
\hline & ${ }^{*}$ sense $\mathrm{e}^{\mathrm{e}}$ & pS-3/535 & (507)CAGCCTGT CGT ATCGCGCAAGTCCGTGTC(535) & & \\
\hline & antisense & pA-3/590 & (620)GCTTTATGATAACAATCTATGAT TCTCACC $(590)$ & & \\
\hline
\end{tabular}

${ }^{a}(*)$ Primer that has been modified to create restriction sites. Unmarked primers are radioactively labeled.

${ }^{b} B s p 1286 \mathrm{I}$ is used to digest revertant-specific PCR generated with pS-2/465:pA-2/483 primers.

'Alternative antisense primer extending next to nucleotide 481 .

${ }^{\mathrm{d}} A l u \mathrm{I}$ is used to digest revertant-specific PCR generated with $\mathrm{pS}-2 / 465: \mathrm{pA}-2 / 482$ primers.

'Shortened sense primer to move 3 ' end away from nucleotide 537. 
Briefly, the original method included reverse transcription of RNA extracted from the virus, amplification by PCR of the genome fragment containing the mutation, digestion of this DNA by restriction enzymes specific for mutant and normal sequences, and quantitation of digestion products after separation by electrophoresis in a polyacrylamide gel (Fig. 1). One of the primers used for PCR was modified to create different restriction sites in normal and mutant sequences. The other primer was $5^{\prime}$ end labeled with [ $\left.{ }^{32} \mathrm{P}\right] \mathrm{ATP}$ and T4 polynucleotide kinase, producing labeled PCR product that facilitated the quantitation of DNA.

\section{Modified MAPREC procedure}

The modified MAPREC procedure also involved cDNA synthesis, but unlike the original protocol, PCR was performed with unlabeled primers, one of which was included at a 10 -fold lower concentration to ensure asymmetric amplification and accumulation of an excess of single strands. The primer complementary to these single strands (the same primer that was used at the previous step

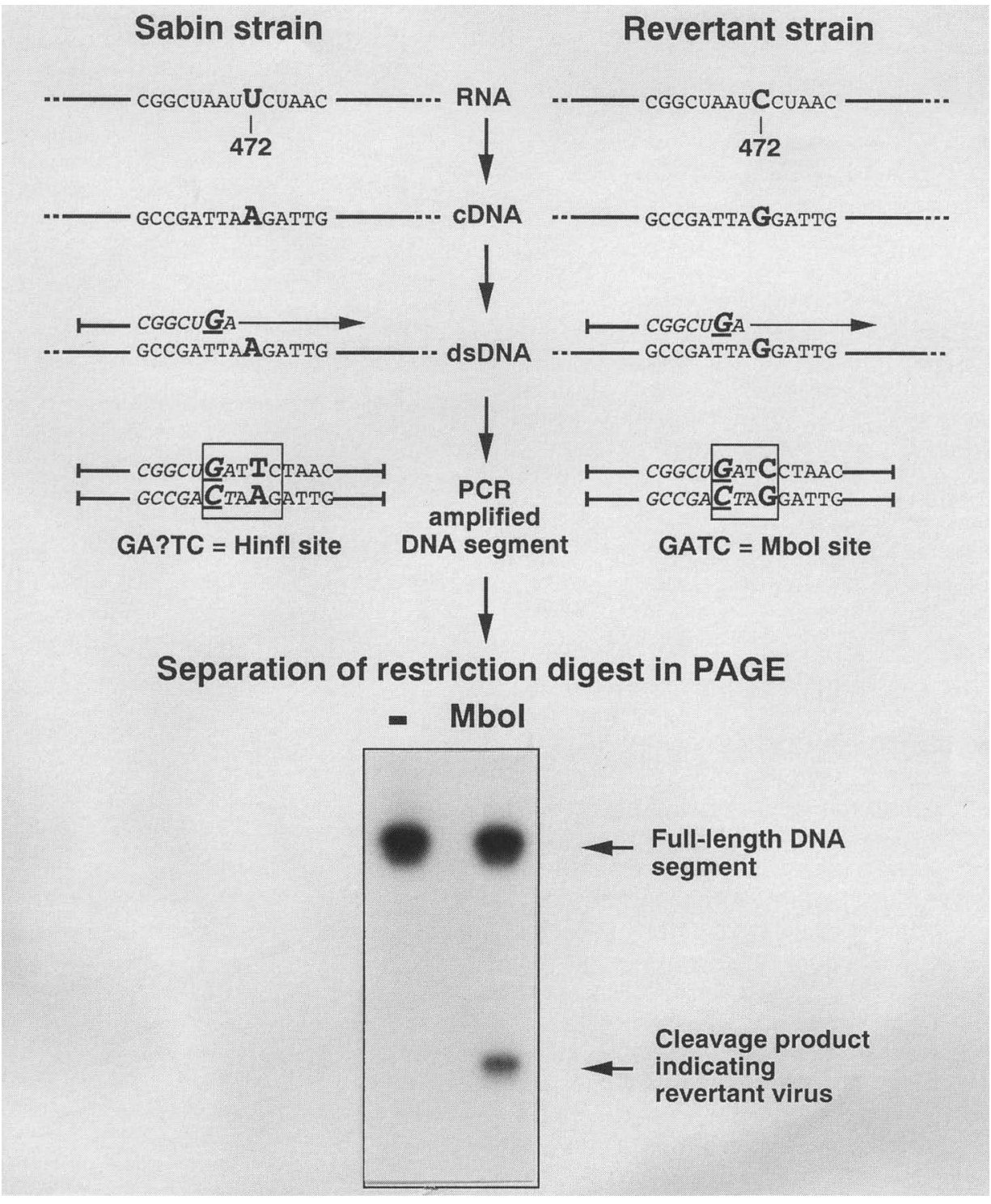

FIGURE 1 Scheme of MAPREC assay. Viral RNA is reverse transcribed, and cDNA is used as a template for PCR amplification of a genome segment containing the nucleotide under study. Partially mismatched primer (shown in italics) is used to create restriction sites for enzymes discriminating between original and mutant sequences. Mutant quantitation is performed after separation of restriction digests of radioactively labeled DNA in polyacrylamide gel.

can be used here) was then radiolabeled and used in a DNA-polymerase primer extension reaction to generate labeled double-stranded DNA. The final steps, that is, enzyme digestion, polyacrylamide gel separation, and quantitation of restriction fragments, were the same as in the original protocol. This modification prevented strand reassortment because at no step of the procedure was labeled DNA exposed to temperatures exceeding the temperature of DNA melting.

\section{Quantitation of DNA by PCR}

Quantitation of DNA by PCR with a reference DNA fragment was performed by quantitative competitive PCR. ${ }^{(4,5)}$ Reference DNA fragment (rfDNA) was prepared by PCR amplification of the same region of the viral genome using a partially mismatched primer that either created a new restriction site or eliminated the existing restriction site. Therefore, rfDNA could be distinguished from the normal DNA in a mixture by digestion with the corresponding enzyme. In the case of assay for position 481 of type 2 OPV, rfDNA lacked Hinfl site at position 440. To determine the relative concentrations of cDNAs, we made serial dilutions of cDNA samples and used them to seed PCR with a constant amount of rfDNA. Amplified DNA was digested with Hinfl to determine the fraction of rfDNA, which enabled us to calculate the relative concentrations of different cDNA samples.

\section{RESULTS}

\section{Formation of Heteroduplexes}

In our earlier studies we showed that quantitative analysis of $\mathrm{U} \rightarrow \mathrm{C}$ revertants at position 472 of type- 3 OPV allows the identification of vaccine lots with increased content of these revertants that would fail the monkey neurovirulence test. Mutant quantitation performed by MAPREC was shown to produce linear results. ${ }^{(1)}$ In type-1 and type-2 OPV, other mutations in the same domain of the 5'-untranslated region are responsible for attenuation. In our recent study, we have demonstrated that both $\mathrm{G} \rightarrow \mathrm{A}$ reversion at position 480 of type $1 \mathrm{OPV}$ and $A \rightarrow G$ reversion at position 481 of type 2 accumulate during passaging of 
the viruses in vitro. ${ }^{(6)}$ While analyzing MAPREC results for these reversions, we noticed that the total of vaccine and revertant sequences was $<100 \%$, and no other nucleotide ( $\mathrm{C}$ or $\mathrm{U}$ ) was detected at these positions. To study this nonadditivity, we made mixtures of type- 2 cDNA with varying proportions of 481-A and 481-G and used them to seed PCR. PCR samples were then digested with AflIII, specific for 480-A (vaccine type) and Bsp1286I, specific for $480-\mathrm{G}$ (wild type). Figure $2 \mathrm{~A}$ shows that results are nonlinear and nonadditive; digestion with both enzymes leaves a substantial proportion of DNA uncut.

This significant deviation from linearity prompted us to reinvestigate the additivity of the assay for mutation at nucleotide 472 of type 3 . Figure $3 \mathrm{~A}$ shows that determination of $472-C$ revertant by digestion with $\mathrm{MboI}$ was linear, whereas digestion with vaccine-spe-

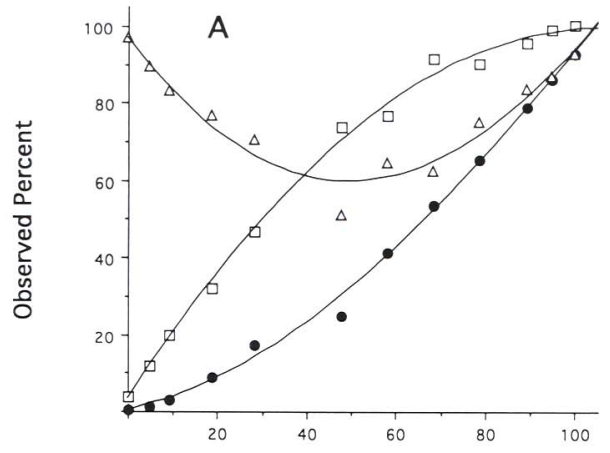

Expected Percent of 481-G

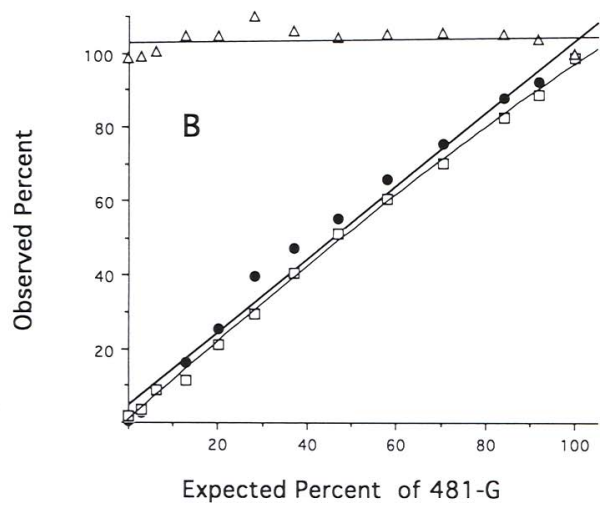

FIGURE 2 Determination of 481-A and 481-G in cDNA mixtures by the original $(A)$ and modified $(B)$ MAPREC methods. Mixtures were made from $100 \% \mathrm{~A}$ and $100 \% \mathrm{G}$ type-2 poliovirus cDNAs, amplified in PCR. Apparent fraction of revertants was determined by digestion with Bsp1286I detecting 481-G (O) and AflIII detecting 481-A ( $\square, 100 \%-481-A)$. $(\triangle)$ The sum of $481-A$ and $481-G$.

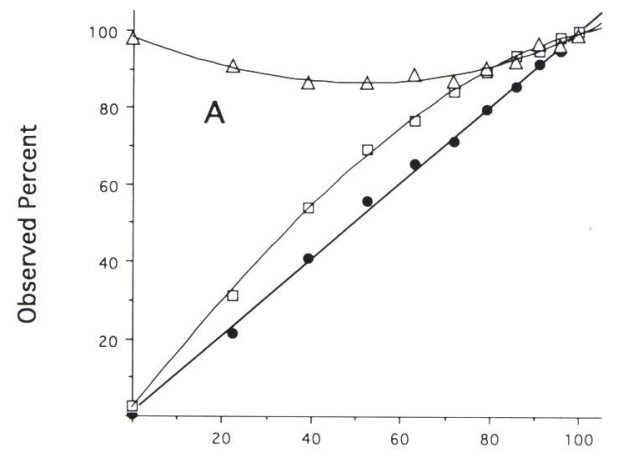

Expected Percent of 472-C

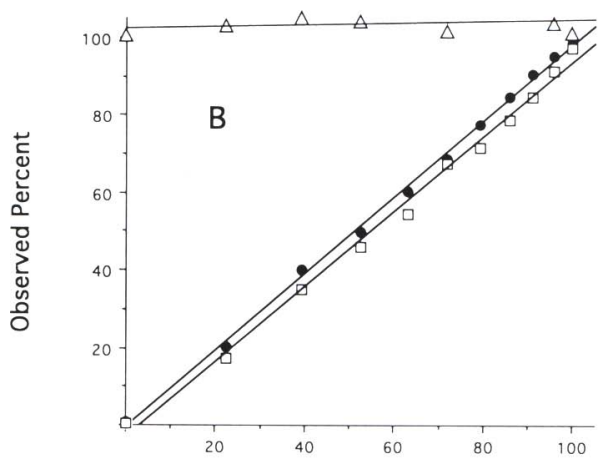

Expected Percent of $472-\mathrm{C}$

FIGURE 3 Determination of 472-T and 472-C in CDNA mixtures by the original $(A)$ and modified (B) MAPREC methods. Mixtures were made from $100 \% \mathrm{~T}$ and $100 \% \mathrm{C}$ type- 3 DNAs, amplified in PCR. Apparent fractions of 472-C (O) and 472-T $(\square, 100 \%-472-\mathrm{T})$ were determined by digestion of amplified DNA with $M b o I$ and Hinfl, respectively. $(\triangle)$ The sum of $472-\mathrm{T}$ and $472-\mathrm{C}$.

cific HinfI produced slightly nonlinear results. Digestion of a $50 \% 472-\mathrm{C}$ sample with both enzymes left $\sim 10 \%$ of DNA uncut.

Therefore, the lack of additivity of assays targeted at vaccine-specific and revertant-specific sequences seems to be a general problem, quantitatively varying for different mutations. One of the possible explanations of the test nonadditivity is that during PCR amplification heteroduplexes that are not susceptible to digestion by either enzyme are formed. This heteroduplex formation can occur at later cycles of PCR by reassortment of DNA strands synthesized in previous cycles. Therefore, we modified the assay by adding the labeled primer only before the last cycle of amplification begins in an attempt to exclude reassortment of full-length DNA strands. This modification reduced the amount of DNA re- sistant to both vaccine- and revertantspecific enzymes but did not restore additivity completely (results not shown). Thus, strand reassortment probably can occur even within one cycle of PCR amplification, presumably because new DNA strands can be synthesized very rapidly during the cooling step even before the binding of complementary strands becomes irreversible. To prevent this reassortment completely, we excluded melting and annealing steps from the labeling reaction. Therefore, we performed PCR with unlabeled primers used at a $1: 10$ ratio to ensure asymmetric amplification and generation of an excess of one strand, and then labeled DNA by extension of the $5^{\prime}-{ }^{32}$ P-labeled primer with Taq DNA polymerase. This modification restored linearity and additivity of assays for both position 481 of type-2, and position 472 of type-3 OPV completely (Figs. 2B and 3B). Similarly, modified PCR/primer extension MAPREC assays for other positions that we studied, for example, reversion at position 480 and 525 of type- 1 OPV, also resulted in completely linear data (Fig. 4).

\section{Nucleotide Misincorporation}

Another potential artifact is exemplified by the assay for mutation at nucleotide 537 of the type-3 OPV. Using MAPREC with a sense primer having the $3^{\prime}$ end at position 536, we could detect 537-A in-

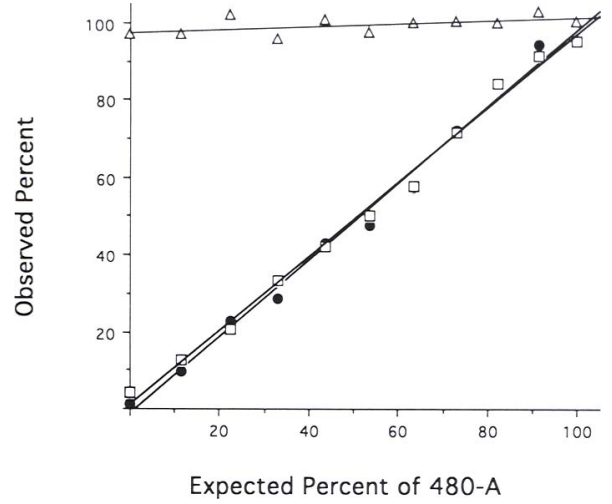

FICURE 4 Determination of $480-\mathrm{A}$ and $480-\mathrm{G}$ in CDNA mixtures by the original $(A)$ and modified $(B)$ MAPREC methods. Mixtures were made from $100 \% \mathrm{~A}$ and $100 \% \mathrm{G}$ type- 1 DNAs, amplified in PCR. Apparent fractions of 480-A (O) and 480-G ( $\square, 100 \%-480-G)$ were determined by digestion of amplified DNA with $A l u \mathrm{I}$ and $A v a \mathrm{I}$, respectively. $(\triangle)$ The sum of $480-\mathrm{A}$ and $480-\mathrm{G}$. 
stead of normal 537-G in some samples (Fig. 5A). The presence of 537-A in OPV was not reproducible and varied significantly in different experiments performed with the same sample. The first nucleotide added to the primer by Taq DNA polymerase often is a hot site of nucleotide misincorporation (A. Gudkov, pers. comm.). When we used a shorter sense primer, with the $3^{\prime}$ end at nucleotide 535, no 537-A was detected. We concluded that 537-A, which was observed with a longer primer, was a result of misincorporation by Taq DNA polymerase. Another example of biased incorporation of nucleotide immediately adjacent to the $3^{\prime}$ end of a primer is provided by the alternative assay for reversion at position 481 of type 2 . When we tested 481-A/481-G mixtures described in Figure 2 with an alternative assay using a primer with a $3^{\prime}$ end at the nucleotide next to position 481 , the results were markedly nonlinear, unlike the assay using a shorter primer with $3^{\prime}$ end shifted one nucleotide farther from nucleotide 481 (results not shown).

Taq DNA polymerase is known to pos-

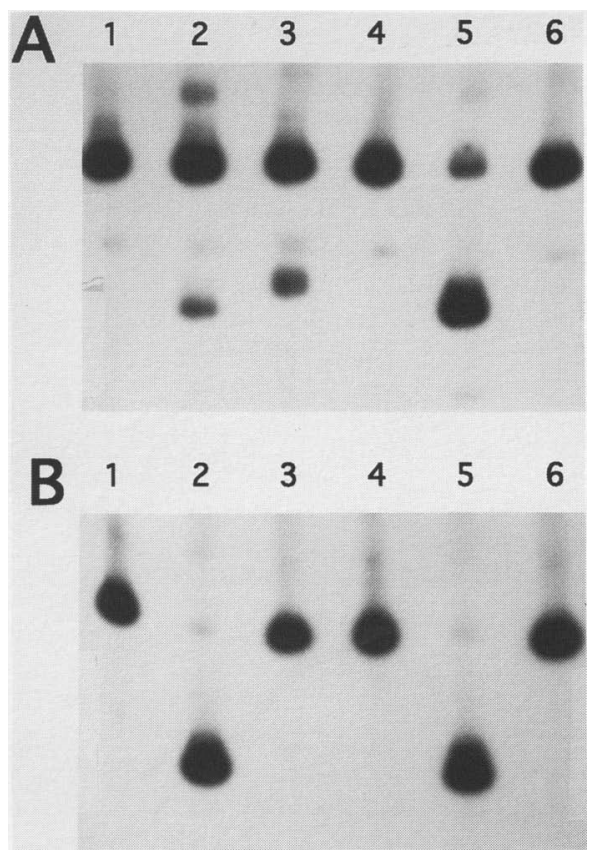

FIGURE 5 Test for mutation at nucleotide 537 of type-3 OPV performed with longer and shorter primers. Type-3 OPV CDNA was amplified with $\mathrm{pS}-3 / 536(A)$, and pS-3/535 $(B)$ primers. PCR DNA was digested with NlaIV (lanes 2,5 ) to detect vaccine sequences, and TaqI (lanes 3,6) to detect revertants. Lanes 1 and 4 contain undigested DNA.

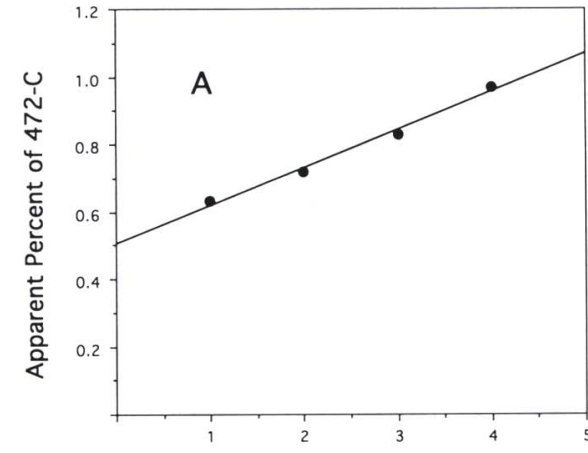

PCR Passage

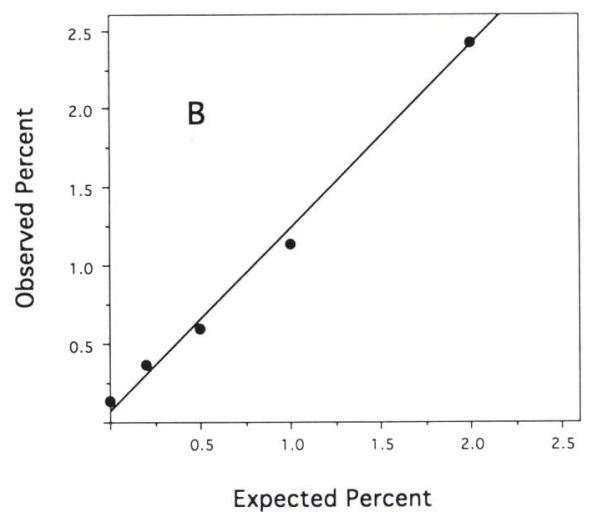

FIGURE 6 PCR passaging of a fragment of type-3 OPV genome $(A)$ and a calibration line for MAPREC assay for position 472 in type-3 OPV $(B)$. DNA sample containing $0.5 \% 472-C$ was passaged in PCR by seeding with $10^{-5}$ dilutions $(A)$. Mixtures of $100 \%$ 472-T and $10 \%$ 472-C DNAs were tested by MAPREC $(B)$.

sess a relatively low fidelity, displaying a specific pattern of preferred types of misincorporation. ${ }^{(7,8)}$ As the above example shows, biased incorporation may occur at an increased rate at the nucleotide immediately adjacent to the $3^{\prime}$ end of a primer, but it can occur in the internal parts of a transcribed sequence as well. This can be demonstrated by serial "PCR passaging" of a DNA fragment of type-3 OPV. DNA template containing $0.5 \%$ of $472-\mathrm{C}$ increased the apparent $472-\mathrm{C}$ content to $\sim 1 \%$ after passaging four times (Fig. 6A). The calibration line presented in Figure 6B shows that when PCR was seeded with a $100 \% 472$-T sample, the apparent content of revertants was $\sim 0.15 \%$.

\section{DISCUSSION}

The problems arising from the use of PCR, described in this paper, are attributed to two separate phenomena. The first one is the formation of heteroduplexes that are resistant to restriction enzyme digestion. Strand reassortment occurs at temperatures higher than the temperature of DNA elongation, that is, $72^{\circ} \mathrm{C}$. Because heteroduplexes can be detected even if labeled DNA was not subjected to melting and reannealing steps, they probably are formed by reassortment of nascent and presumably incomplete strands synthesized during a rapid cooling from $94^{\circ} \mathrm{C}$ to $72^{\circ} \mathrm{C}$. This means that Taq DNA polymerase may copy DNA before irreversible annealing of primer and template occurs. Avoiding temperatures above $72^{\circ} \mathrm{C}$ after labeled DNA was synthesized eliminates labeled heteroduplex formation. Therefore, the modified MAPREC protocol, including PCR amplification, to make singlestranded DNA followed by radiolabeling during second-strand DNA synthesis by primer extension should be used for mutant quantitation.

The second artifact evidently results from the intrinsic inaccuracy of Taq DNA polymerase. We observed an accumulation of particular mutants when the DNA fragment was serially "passaged" in PCR. In the case of nucleotide 472 of type-3 OPV, $\sim 0.1-0.15 \%$ of the revertant accumulated in each PCR amplification experiment. This implies that special homogenous negative controls with no revertants should be included when sensitive MAPREC tests are performed to detect very low amounts of revertant sequences. Nucleotide misincorporation by Taq DNA polymerase was shown to possess a specific biased pattern with 20 times higher frequency of $\mathrm{T} \rightarrow \mathrm{C}$ misincorporation compared with $\mathrm{C} \rightarrow \mathrm{T}$ misincorporation. ${ }^{(7,8)}$ Our results on the accumulation of $472-C$ in PCR passages of DNA are consistent with this pattern. Additional information about nucleotide misincorporation is that it may be, at least in some cases, affected by proximity of the 3' end of the template. Misincorporation of $A$ instead of $G$ at nucleotide 537 of type- 3 OPV was reduced significantly when the $3^{\prime}$ end was moved away from this position.

It is noteworthy that the direction of nucleotide change occurring in PCR passaging at nucleotide 472 of type- 3 OPV is the same as that observed in this virus in vivo. ${ }^{(9)}$ Upon passaging of the Sabin type-3 OPV strain in cell culture, 472-C substitutes original vaccine-specific 472 $\mathrm{U}$. This reversion, at least in part, is be- 
lieved to be caused by a selective advantage of the revertant resulting from a higher affinity of its RNA to protein synthesis initiation factors. ${ }^{(10)}$ It is possible that biased nucleotide incorporation by the viral RNA polymerase can also contribute to the revertant accumulation in vivo .

\section{ACKNOWLEDGMENTS}

This work was supported in part by grant 9102A01 from the National Vaccine Program Office. We thank Drs. Igor Roninson and Andrej Gudkov for suggestions and Drs. Inessa Levenbook and Edward Fitzgerald for their support.

\section{REFERENCES}

1. Chumakov, K.M., L.B. Powers, K.E. Noonan, I.B. Roninson, and I.S. Levenbook. 1991. Correlation between amount of virus with altered nucleotide sequence and the monkey test for acceptability of oral poliovirus vaccine. Proc. Natl. Acad. Sci. 88: 199-203.

2. Chumakov, K.M., L.P. Norwood, M.L. Parker, E.M. Dragunsky, Y. Ran, and I.S. Levenbook. 1992. RNA sequence variants in live poliovirus vaccine and their relation to neurovirulence. J. Virol. 66: 966970.

3. Chumakov, K., L. Norwood, M. Parker, R. Taffs, Y. Ran, J. Ridge, and I. Levenbook. 1993. Assessment of the viral RNA sequence heterogeneity for control of OPV neurovirulence. Dev. Biol. Stand. 78: 7989.

4. Perrin, S. and G. Gilliland. 1990. Site-specific mutagenesis using assymmetric polymerase chain reaction and single mutant primer. Nucleic Acids Res. 18: 7433-7438.

5. Stieger, M., C. Demoliere, L. AhlbornLaake, and J. Mous. 1991. Competitive polymerase chain reaction assay for quantitation of HIV-1 DNA and RNA. I. Virol. Methods 34: 149-160.

6. Chumakov, K.M., E.M. Dragunsky, L.P. Norwood, M.P. Douthitt, Y. Ran, R.E. Taffs, J. Ridge, and I.S. Levenbook. 1993. Consistent selection of mutations in the 5 -untranslated region of oral poliovirus vaccine upon passaging in vitro. J. Med. Virol. (in press).

7. Kunkel, T.A. and K.A. Eckert. 1989. Polymerase chain reaction. In Current communications in molecular biology (ed. H.A. Erlich, R. Gibbs, and H.H. Kazazian), pp. 5-10. Cold Spring Harbor Laboratory Press, Cold Spring Harbor, New York.

8. Tindall, K.R. and T.A. Kunkel. 1988. Fidelity of DNA synthesis by the Thermus aquaticus DNA polymerase. Biochemistry 27: 6008-6013.
9. Evans, D.M.A., G. Dunn, P.D. Minor, G.C. Schild, A.J. Cann, G. Stanway, J.W. Almond, K. Currey, and J.V. Maizel Jr. 1984. Increased neurovirulence associated with a single nucleotide change in a noncoding region of the Sabin type-3 poliovirus genome. Nature 314: 548-550.

10. Svitkin, Y.V., N. Cammac, P.D. Minor, and J.W. Almond. 1990. Translation deficiency of the Sabin type 3 poliovirus genome: Association with an attenuating mutation $\mathrm{C}_{472} \rightarrow \mathrm{U}$. Virology 175: 103109.

Received June 21, 1993; accepted in revised form September 23, 1993. 


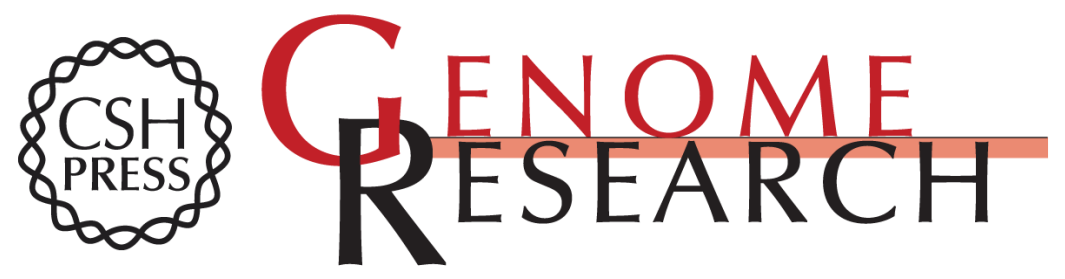

\section{Quantitative aspects of the mutant analysis by PCR and restriction enzyme cleavage (MAPREC).}

Z Lu, M P Douthitt, R E Taffs, et al.

Genome Res. 1993 3: 176-180

References This article cites 8 articles, 2 of which can be accessed free at: http://genome.cshlp.org/content/3/3/176.full.html\#ref-list-1

License

Email Alerting

Receive free email alerts when new articles cite this article - sign up in the box at the Service top right corner of the article or click here.

\section{Affordable, Accurate Sequencing.}

To subscribe to Genome Research go to: https://genome.cshlp.org/subscriptions 